Cite this: RSC Adv., 2014, 4, 27888

\title{
Substrate porosity induces phenotypic alterations in retinal cells cultured on silicon nanowires $\dagger$
}

\author{
Gaëlle Piret, ${ }^{\text {abcd }}$ Maria-Thereza Perez ${ }^{\star c d e}$ and Christelle N. Prinz ${ }^{\star a b d}$
}

Arrays of silicon nanowires (Si NW) may be used in the development of implantable drug delivery systems. Here, we performed short- and long-term cultures of mouse retinal cells on substrates consisting of high aspect ratio Si NW, which confers high porosity to the surface. As controls, cells were grown on flat silicon substrates. The cell phenotype was assessed using immunocytochemistry, fluorescence microscopy and scanning electron microscopy. We observed that, despite good adhesion and long-term survival on $\mathrm{Si}$ NW (for at least 18 days in vitro), cells underwent striking phenotypic changes, characterized by the absence of neurites and an underexpression of most retinal cell markers. These alterations could, however, be prevented by functionalizing the surface using perfluorosilane molecules. The study also provides evidence that the altered cell behavior on Si NW can be attributed to contaminants entrapped in the nanowire array. Our data thus indicate that creating high aspect ratio pores, while increasing porosity in order to increase the loading capacity of the substrate, results in neurotoxicity. The functionalized substrates, while allowing for cell growth, would not be suitable for drug delivery. The findings are important for the design of porous silicon-based cell scaffolds and drug delivery systems, in particular when aimed at interfacing CNS cells.

Received 5th May 2014

Accepted 10th June 2014

DOI: $10.1039 / c 4 r a 04121 f$

www.rsc.org/advances
The most commonly used pSi topographies consist of isotropic and shallow pores, where cell viability and adhesion have been shown to be better, compared to flat substrates. The situation is, on the other hand, less clear for high aspect ratio pSi, such as silicon pillars, silicon grass and Si NW.,15-18 The latter are of particular interest for biomedical applications since the demonstration that nanowire-structured silicon surfaces, due to their greater substrate porosity, have a higher drug-load capacity and may therefore be used for slow and long-lasting release of, for instance, antibiotics. ${ }^{7}$ These observations open the possibility of using implants based on Si NW substrates to deliver therapeutic agents also to various areas of the central nervous system (CNS), including the retina.

We have previously shown that gallium phosphide (GaP) nanowires are excellent substrates for neural cell cultures, ${ }^{\mathbf{1 9 - 2 4}}$ particularly in the case of retinal cells, ${ }^{22}$ where long nanowires promoted exceptional neurite outgrowth and long-term survival of multiple cell types, compared to short nanowires and flat controls. Based on these observations, we anticipated that arrays of long Si NW would be similarly favorable in supporting cell survival and growth of retinal cells.

In the present study, we cultured postnatal day 4 (PN4) mouse retinal cells on Si NW substrates produced using metal assisted chemical etching (MACE), which produces high aspect ratio pores in $\mathrm{Si}^{25,26} \mathrm{We}$ assessed the cell distribution, morphology, as well as the expression of retinal cell functional markers using immunocytochemistry after 3 and 18 days in vitro (DIV) on Si NW and used flat silicon substrates as controls. christelle.prinz@ftf.lth.se

${ }^{b}$ Neuronano Research Center, Lund University, Sweden

${ }^{c}$ Department of Clinical Sciences, Division of Ophthalmology, Lund University, SE-221 84 Lund, Sweden. E-mail: maria_thereza.perez@med.lu.se

${ }^{d}$ The Nanometer Structure Consortium, Lund University, Sweden ${ }^{e}$ Department of Ophthalmology, Glostrup Hospital, Glostrup, Denmark

$\dagger$ Electronic supplementary information (ESI) available. See DOI: 10.1039/c4ra04121f 


\section{Experimental section}

Animals

Wild-type mice (C3H/HeA background, own colonies) were kept on a 12 hour light-dark cycle, with free access to food and water. All experiments were approved by the local committee for animal experimentation and ethics. Handling of animals was in accordance with the ARVO Statement for the Use of Animals in Ophthalmic and Vision Research.

\section{Silicon substrate controls}

Control substrates, denominated flat silicon ("flat Si" or "Si flat" in Figures) consisted of (100) n-type (phosphorus) silicon wafers with a resistivity of 1-10 Ohm $\mathrm{cm}$ (University Wafer, http:// www.universitywafer.com).

\section{Silicon nanowire substrate}

Si NW substrates were prepared by metal assisted chemical etching (MACE) of crystalline silicon in hydrofluoric acid (HF)/ silver nitrate $\left(\mathrm{AgNO}_{3}\right)$ aqueous solution, as previously described. ${ }^{16}$ In brief, silicon wafers [as those used as controls: (100) n-type (phosphorus), resistivity of 1-10 Ohm $\mathrm{cm}]$, were cleaned in acetone and isopropanol, rinsed in Milli-Q water (Merck Millipore, Billerica, USA) and immersed in a piranha solution ( $3: 1$ concentrated $\mathrm{H}_{2} \mathrm{SO}_{4}: 30 \% \mathrm{H}_{2} \mathrm{O}_{2}$ ) for 15 min at 80 ${ }^{\circ} \mathrm{C}$, followed by copious rinsing in Milli-Q water. Arrays of Si NW were obtained by chemical etching of the substrate in $\mathrm{HF}$ / $\mathrm{AgNO}_{3}(6.3 \mathrm{M} / 0.02 \mathrm{M})$ Milli-Q water solution at $55^{\circ} \mathrm{C}$ for $10 \mathrm{~min}$. Silver was removed by immersing the substrates in two successive 4 hour-long baths of nitric acid $\left(\mathrm{HNO}_{3}\right)$ at room temperature, rinsing in Milli-Q running flow during $1 \mathrm{~min}$ and further rinsing in a Milli-Q water bath overnight. Fig. 1 shows scanning electron microscopy (SEM) images of the main type of Si NW substrates used in this study, with $4.4 \mu \mathrm{m}$ long nanowires of diameter ranging from 20 to $120 \mathrm{~nm}$. Nanowires of different lengths (200 nm, $800 \mathrm{~nm}$ and $1.8 \mu \mathrm{m}$ ) were also prepared with 1 min, $3 \mathrm{~min}$ and $6 \mathrm{~min}$ etching durations, respectively.

Control flat Si substrates and Si NW substrates of about the same size were used in the cell cultures. Before cell seeding, substrates were incubated in $70 \%$ ethanol for $10 \mathrm{~min}$, air-dried overnight and placed in sterile 4-well culture chambers (Nunc Lab-Tek II Chamber Slide System, Thermo Scientific, Denmark; code: 177399).

Safety considerations when using HF: hydrofluoric acid is a hazardous acid, which can result in serious tissue damage if burns are not appropriately treated. Etching of silicon should be performed in a well-ventilated fume hood with appropriate safety considerations: face shield, apron and double-layered nitrile gloves should be used.

\section{Patterns of nanowires}

Square arrays with nanowires $\left(50 \times 50 \mu \mathrm{m}^{2}\right)$ with a periodicity of $100 \mu \mathrm{m}$ were made using optical lithography. S1818 photoresist (Rohm and Haas Electronic Materials, Marlborough, MA, USA; code: 10277866) was spun-coated onto a silicon wafer at 3500
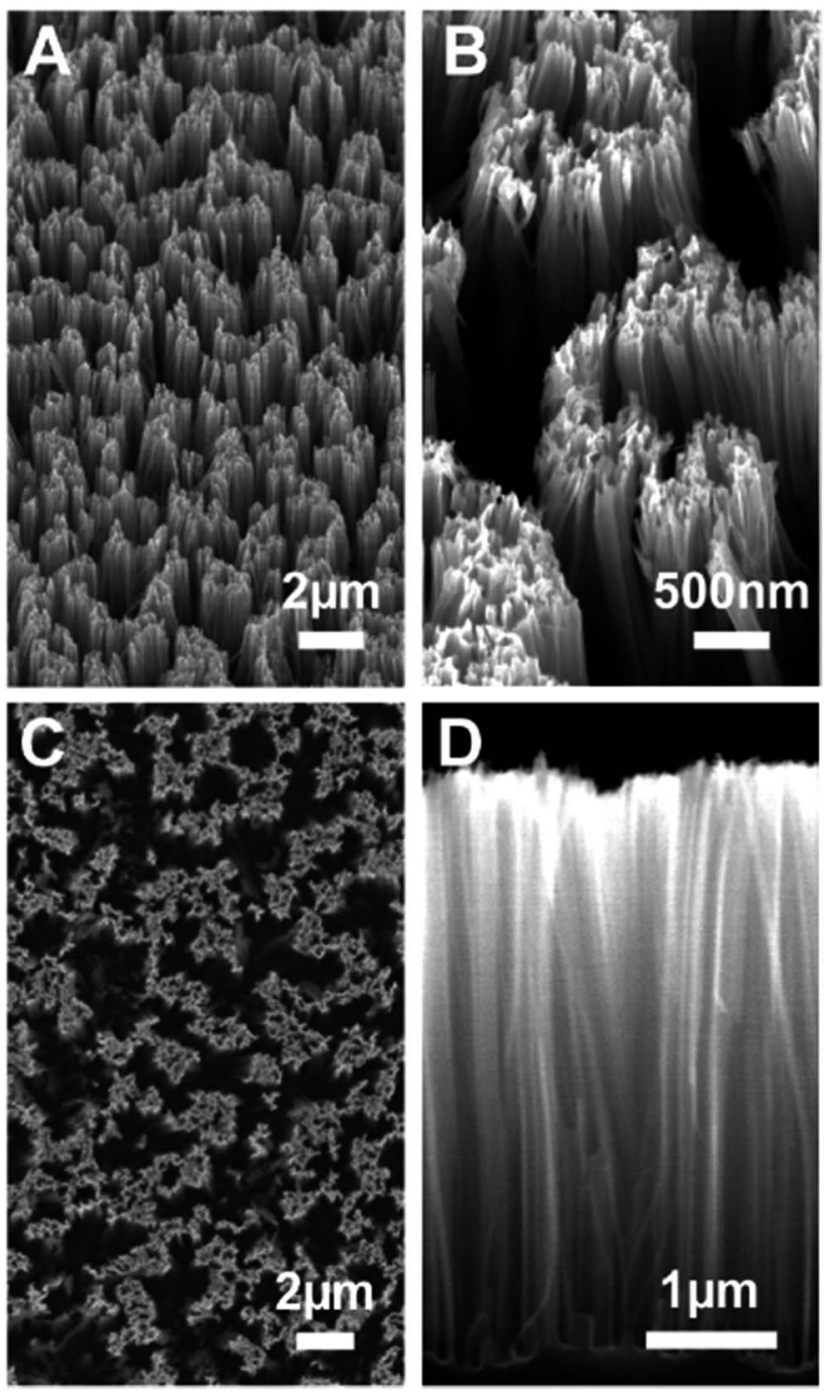

Fig. 1 SEM images showing the Si NW topography mainly used in this study: tilted view at $30^{\circ}(\mathrm{A})$, high magnification, tilted view at $20^{\circ}(\mathrm{B})$, top view (C), side view (D). Scale bars, $2 \mu \mathrm{m}$ in (A), $500 \mu \mathrm{m}$ in (B), $2 \mu \mathrm{m}$ in (C), and $1 \mu \mathrm{m}$ in (D).

rpm and soft backed at $120{ }^{\circ} \mathrm{C}$ for $90 \mathrm{~s}$. To define apertures, optical lithography was carried out by exposing the resist to UV light (360 W Hg lamp) through a designed mask (ordered from Delta Mask BV, Enschede, The Netherlands) for $12 \mathrm{~s}$, using a MJB4 mask aligner (Süss Microtech AG, Garching, Germany). The sample was then dipped in MF319 developer (Rohm and Haas Electronic Materials, Marlborough, MA, USA; code: 10058721) for $60 \mathrm{~s}$, thoroughly rinsed in Milli-Q water, and dried under nitrogen flow. The samples were cleaned using a $5 \mathrm{mbar}$ oxygen plasma for $1 \mathrm{~min}$ (Plasma Preen, Plasmatic Systems, Inc., North Brunswick, USA).

The resulting exposed parts of the substrate were etched in $\mathrm{HF} / \mathrm{AgNO}_{3}(6.3 \mathrm{M} / 0.02 \mathrm{M})$ aqueous solution at room temperature for $8 \mathrm{~min}$, resulting in $1.8 \mu \mathrm{m}$ long nanowires of diameter ranging from 20 to $120 \mathrm{~nm}$. The resist was removed in acetone and the samples were then rinsed in isopropanol. Silver was removed by putting the samples in two successive 4 hour-baths 
of $\mathrm{HNO}_{3}(10.6 \mathrm{M})$ solution at room temperature and subsequent thorough rinsing in deionised water.

\section{Silicon substrates decorated with Ag nanoparticles}

Flat silicon substrates were immersed in $\mathrm{HF} / \mathrm{AgNO}_{3}(2.63 \mathrm{M} / 5$ $\times 10^{-4} \mathrm{M}$ ) at room temperature during $60 \mathrm{~s}$, rinsed in Milli-Q water and dried under nitrogen flow.

\section{Extra cleaning steps}

We performed additional cleaning steps for Si NW substrates using either a water bath, exposure to high vacuum or plasma etching. Specifically, Si NW substrates were left overnight in $10 \mathrm{~mL}$ Milli-Q water at room temperature, or in two successive 1 hour-baths in $10 \mathrm{~mL}$ Milli-Q water at $80^{\circ} \mathrm{C}$. Alternatively, Si NW substrates were exposed to high vacuum $\left(10^{-9} \mathrm{mbar}\right)$ overnight in an Electron Beam Lithography chamber (Raith 150, Raith, Dortmund, Germany). Finally, some Si NW substrates were cleaned for 5 min using a $100 \mathrm{mT}, 150 \mathrm{~W} \mathrm{O}_{2}$ plasma (Etching (RIE) system T2, Trion Technology, Tempe, USA).

\section{BSA coating}

The substrates were incubated for $30 \mathrm{~min}$ at room temperature in BSA (Sigma Aldrich; code A7906) at $10 \mathrm{mg} \mathrm{mL}^{-1}$ dissolved in sterile phosphate buffered saline (PBS) $(10 \mathrm{mM}, \mathrm{pH}=7.2)$ and filtered with a $0.22 \mu \mathrm{m}$ pore filter (SARSTEDT, Germany; code: 83-1826-001). The substrates were then rinsed with PBS for $2 \times$ $10 \mathrm{~min}$. The substrates were kept in PBS for a maximum of 60 min before seeding the cells.

\section{Poly-D-lysine/laminin coating}

The substrates were incubated for 1 hour at $37^{\circ} \mathrm{C}$ in a poly-Dlysine (Sigma Aldrich Sweden AB; code: P7405) at $10 \mu \mathrm{g} \mathrm{mL}$ dissolved in sterile water, rinsed with sterile water and dried. A laminin solution (Sigma Aldrich; code: L2020) at $5 \mu \mathrm{g} \mathrm{mL} \mathrm{m}^{-1}$ in Milli-Q water was subsequently added to the substrate for $30 \mathrm{~min}$ at $37{ }^{\circ} \mathrm{C}$, and rinsed $2 \times 5 \mathrm{~min}$ in sterile PBS. The substrates were kept in PBS for a maximum of $60 \mathrm{~min}$ before seeding the cells.

\section{Perfluorosilane (PFS) covalent bonding}

A solution of $1 H, 1 H, 2 H, 2 H$-perfluorooctyltrichlorosilane (ABCR, Germany; code: AB104054) was used to prepare hydrophobic flat silicon surfaces and super-hydrophobic Si NW surfaces. Both substrate types were placed next to $20 \mu \mathrm{L}$ of the silane stock solution in a closed vessel and warmed up to $160^{\circ} \mathrm{C}$ on a hot plate for 3 hours. The substrates were rinsed with dichloromethane, isopropanol, water and dried under nitrogen flow.

\section{Primary retinal cell culture}

Retinal cell cultures were prepared as previously described. ${ }^{22}$ Briefly, retinas from postnatal (PN) day 4 mice were isolated free from retinal pigment epithelium under R16 serum-free culture medium (Invitrogen Life Technologies; code 07490743A) and transferred thereafter to a digestion solution $(0.75 \mathrm{~mL} /$ retina;
$30 \mathrm{~min}$ at $\left.37^{\circ} \mathrm{C}\right) .{ }^{22}$ After the digestion, the retinal tissue was rinsed and thereafter dissociated in $2 \mathrm{~mL}$ of culture medium [Dulbecco's modified Eagle's Medium (DMEM) (Invitrogen Life Technologies; code 41966-029) containing 2\% of B27-supplement (Invitrogen Life Technologies; code 17504-044) and 2\% of L-glutamine-penicillin-streptomycin solution (Sigma-Aldrich; code G6784)]. The cell suspension was transferred to a vial containing $48 \mathrm{~mL} \mathrm{DMEM}$ and centrifuged at $900 \times g$ for $5 \mathrm{~min}$ at room temperature. The cell pellet was re-suspended in the culture medium solution (2.27 $\mathrm{mL}$ per retina) and the suspension passed through a $40 \mu \mathrm{m}$ nylon mesh (BD Biosciences, USA; code 352340 ). Approximately $9 \times 10^{4}$ cells were seeded onto each well, each one containing one type of Si NW or flat silicon substrate. Each type of substrate was tested in at least three different culture experiments.

Solutions of $\mathrm{HF}\left(10^{-2} \mathrm{M}\right.$ and $\left.10^{-3} \mathrm{M}\right)$, and of $\mathrm{HNO}_{3}\left(10^{-2} \mathrm{M}\right.$ and $10^{-3} \mathrm{M}$ ) were prepared in culture medium. Fifty $\mu \mathrm{L}$ of each solution was added and mixed with $450 \mu \mathrm{L}$ of the cell suspension, and seeded onto each well. The final concentrations were then, respectively: $\mathrm{HF}$ at $10^{-3} \mathrm{M}, \mathrm{HF}$ at $10^{-4} \mathrm{M}, \mathrm{HNO}_{3}$ at $10^{-3} \mathrm{M}$, $\mathrm{HNO}_{3}$ at $10^{-4} \mathrm{M}$. After $3 \mathrm{DIV}$, the medium was changed and replaced by fresh culture medium, without $\mathrm{HF}$ or $\mathrm{HNO}_{3}$.

\section{Immunocytochemistry}

Following 1, 3 and 18 days in vitro (DIV), cells were fixed with 4\% paraformaldehyde (PFA) dissolved in $100 \mathrm{mM}$ Sørensen's buffer $(\mathrm{pH}=7.4) .{ }^{22}$ After fixation, cells were washed with PBS (10 mM, $\mathrm{pH}=7.2$ ), followed by permeabilization and blocking with Trisbuffered saline (TBS; $10 \mathrm{mM}, \mathrm{pH}$ 7.2) containing $0.25 \%$ Triton $\mathrm{X}-100$ (TBS-T) and 2\% bovine serum albumin (BSA). Cells were thereafter incubated with monoclonal or polyclonal primary antibodies (listed in Table S1 $\dagger$ ), followed by washes with TBS and incubation with one of the following secondary antibodies: DyLight-488 donkey anti-rabbit (Jackson ImmunoResearch Laboratories Inc, USA; code 711-485-152), DyLight-549 donkey anti-mouse (Jackson ImmunoResearch Laboratories Inc, USA; code 715-505-150), Alexa-488 donkey anti-goat (Invitrogen Life Technologies, Sweden; code A11055) or Texas Red donkey antisheep (Jackson ImmunoResearch Laboratories Inc, USA; code 713-076-147) at $1: 200$ for $90 \mathrm{~min}$ at room temperature. The cells were then rinsed with PBS and mounted with VECTASHIELD®, (Vector Laboratories, USA) containing the nucleic acid stain 4'-6-diamidino-2-phenylindole (DAPI) (Vector Laboratories, USA).

\section{Fluorescence microscopy}

Retinal cultures were examined with a wide-field fluorescence microscope (Axiophot, Carl Zeiss Meditec Inc, Germany) using a plan-neofluar objective $(40 \times / 0.75)$. For each of the cell markers analyzed, images were acquired using an exposure time (ET) adapted to the level of fluorescence of the signal. In most cases, it was necessary to increase the ET when imaging cells cultured on Si NW (compared to the time necessary to image cells cultured on flat $\mathrm{Si}$, for which ET was assigned a value $=1$ ). The additional ET needed to image cells cultured on $\mathrm{Si}$ NW substrates is indicated in the Figures. 


\section{Scanning electron microscopy}

Cells were fixed by replacing the culture medium with sodium cacodylate buffer $(100 \mathrm{mM}, \mathrm{pH}=7.4)$ containing $2.5 \%$ of glutaraldehyde. After $30 \mathrm{~min}$, the substrates were rinsed $2 \times 10$ min with fresh buffer and then $10 \mathrm{~min}$ with ultrapure water (resistivity of $18.2 \mathrm{M} \Omega \mathrm{cm}$ ). The substrates were then dehydrated in a series of ethanol solutions and dried using a critical-point dryer (CPD030, Leica Microsystems GmbH, Wetzlar, Germany). Thereafter, they were sputter-coated with $10 \mathrm{~nm}$ of gold-palladium (VG Microtech, UK; SC7640). The scanning electron microscopy study was performed using a LEO SEM 1560, Zeiss (Germany).

\section{Results}

\section{Cell distribution and phenotype}

Retinal cells from 4 day-old mice were cultured on Si NW (Fig. 1) and control Si flat substrates for different periods of time. Already at 1DIV, the cell distribution appeared different on the two types of substrates, with densely packed single cells on the Si NW substrate compared to mainly cell clusters and a few single cells on flat $\mathrm{Si}$ (not shown). The same cell distribution was observed for both substrates at 3DIV and 18DIV, except that on flat $\mathrm{Si}$, areas devoid of cells were noted (Fig. 2A-D). Furthermore, it was found that many cells on flat Si exhibited processes of different lengths (Fig. 2E), whereas cells on Si NW had a spherical shape and did not extend on the substrate (Fig. 2F).

The different retinal cell types were identified using specific cell markers (Table S1 $\dagger$ ). A generic neuronal marker, $\beta$-tubulin III revealed the presence of immunoreactive cells on both types of substrates at 3DIV (Fig. 3) and 18DIV (Fig. S1†). However, the level of $\beta$-tubulin III expression seemed to be lower in Si NW compared to flat Si substrates (Fig. 3A-B). In the latter, some labeled cells were also seen to extend processes, which are likely to correspond to neurites. These were particularly long at 18DIV (Fig. S1A $\dagger$ ), but were not observed with cells cultured on Si NW substrates at 3DIV (Fig. 3B and D) or 18DIV (Fig. S1B $\dagger$ ). The glial cell marker, glial fibrillary acidic protein (GFAP) also localized cells on both substrates at 3DIV and 18DIV. On flat Si, glial cells exhibited a flat, polygonal shape, and were seen in association with clusters (Fig. 3E and $\mathrm{S} 1 \mathrm{C}^{\dagger}$ ), whereas on Si NW, GFAP labeling was only detected in the cell body (Fig. 3F and S1D $\dagger$ ) and at lower levels than in cells on flat $\mathrm{Si}$.

Retinal ganglion cells were labeled using antibodies against TRPV4 and Brn3a. At 3DIV, TRPV4- and Brn3a-positive cells were seen mostly in association with clusters on flat $\mathrm{Si}$ substrates and short, labeled processes were observed within the clusters (Fig. S2A and $\mathrm{C}^{\dagger}$ ). At 18DIV, a large network of labeled processes were occasionally seen (Fig. S1E $\dagger$ ). On Si NW substrates, both markers appeared under-expressed as compared to flat Si substrates and no cell processes could be seen (Fig. S2B and D and S1F†).

Bipolar cells were labeled using antibodies against Chx10 and PKC. Both Chx10- and PKC-positive cells were found at 3DIV on flat Si and Si NW substrates (Fig. S3A-D †), but the
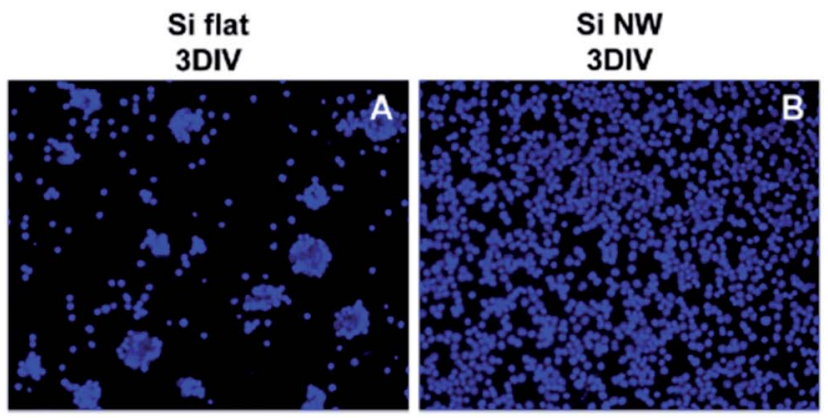

Si flat

18DIV

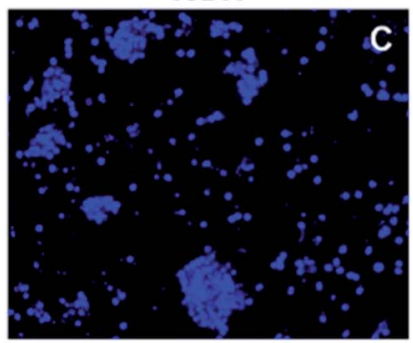

Si flat

18DIV

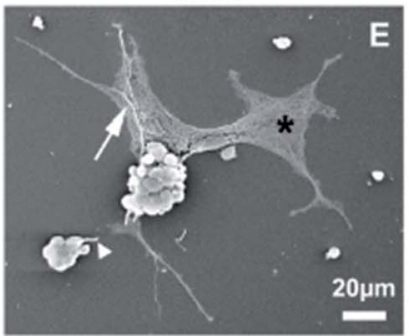

$20 \mu \mathrm{m}$
Si NW

18DIV

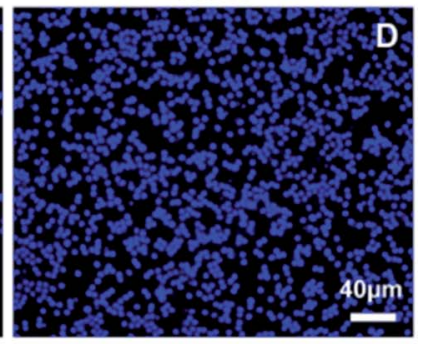

Si NW

18DIV

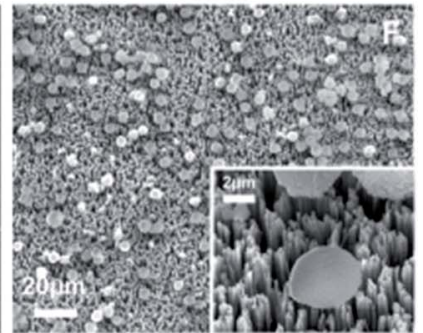

Fig. 2 Fluorescence images of cell nuclei (DAPI, blue) showing the cell distribution on flat and Si NW substrates at 3DIV on flat Si (A) and Si NW (B) substrates and at 18DIV on flat Si (C) and Si NW (D) substrates. SEM images of retinal cells at 18DIV on flat Si (E) and Si NW (F) substrates. Note a large cell(s) (likely to correspond to glia, asterisk) from which cytoplasmic extensions spread on the flat Si surface and how cells in clusters (likely to correspond to neurons) extend processes onto (large arrow) or near (arrowhead) the glial extensions. Scale bar, $40 \mu \mathrm{m}$ for fluorescence images. Scale bars for SEM images, $20 \mu \mathrm{m}$ in (E) tilt $30^{\circ}$, $20 \mu \mathrm{m}$ in (F) tilt $25^{\circ}, 2 \mu \mathrm{m}$ in inset, tilt $30^{\circ}$

levels of expression appeared to be lower in cells found on $\mathrm{Si}$ NW (Fig. S3B and $\mathrm{D}^{\dagger}$ ) compared to those on flat substrate controls (Fig. S3A and $\mathrm{C} \dagger$ ). At 18DIV, Chx10 was still expressed in both substrates (Fig. S4A and $\mathrm{B} \dagger$ ), but PKC could only be detected on flat Si (not shown). We also used an antibody against recoverin, which, in vivo, is expressed by some bipolar cells and by photoreceptors. Labeled cells were observed at 3DIV (Fig. S3E and $\mathrm{F}^{\dagger}$ ) and 18DIV (Fig. S4C and $\mathrm{D} \dagger$ ), but while some recoverin positive cells were seen to exhibit short processes within the clusters on flat Si (Fig. S3E and S4C $\dagger$ ), no process outgrowth was observed on the Si NW substrates (Fig. S3F and $\mathrm{S} 4 \mathrm{D}^{\dagger}$ ). Further, the level of recoverin expression appeared also to be lower on Si NW substrates compared to that observed on flat substrate controls.

Antibodies against arrestin and rhodopsin were, in addition, used to visualize cone and rod photoreceptors, 

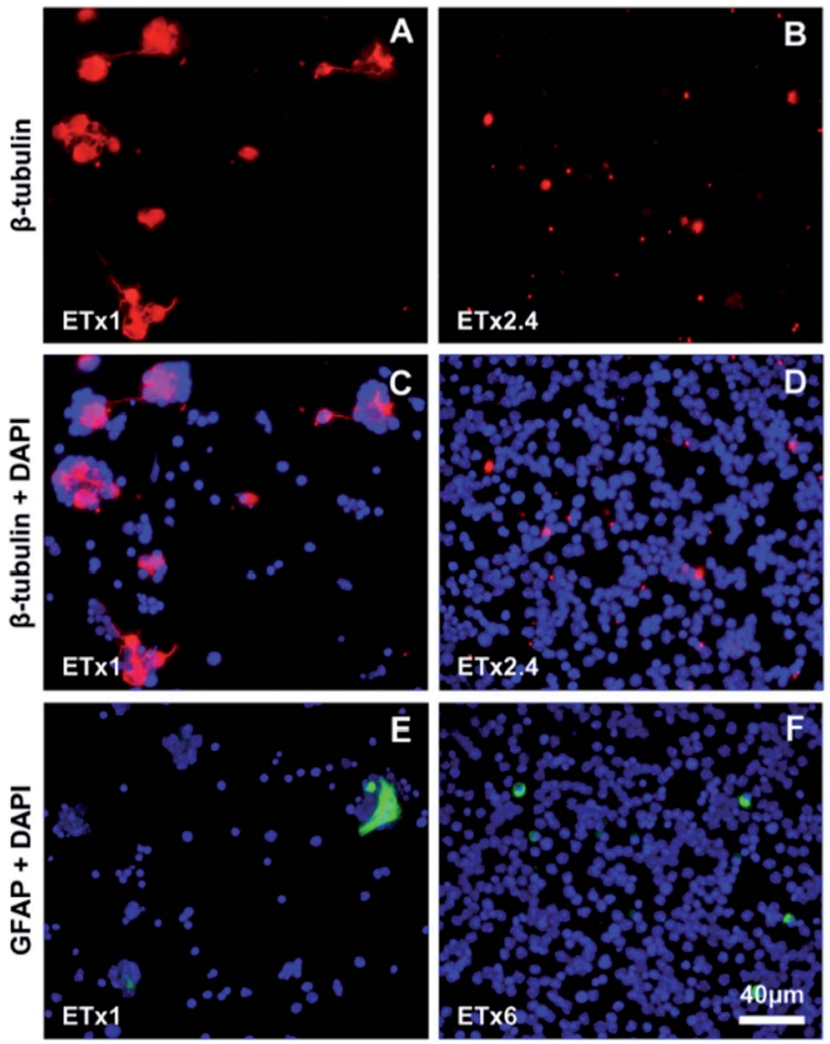

Fig. 3 Fluorescence images of retinal cell cultures after 3 DIV showing $\beta$-tubulin III positive cells (red) on flat Si (A) and Si NW (B) substrates, and $\beta$-tubulin III positive cells (red) together with cell nuclei (DAPI, blue) on flat Si (C) and Si NW (D) substrates. Fluorescence images of retinal cell cultures after 3DIV showing cell nuclei (DAPI, blue) and GFAP positive cells (green) on flat Si (E) and Si NW (F) substrates. The Exposure Time (ET) required to image the cells cultured on Si NW substrates was increased by a factor that is indicated at the bottom left of each panel. Scale bars, $40 \mu \mathrm{m}$ for all panels.

respectively. Some labeled cones were observed on flat $\mathrm{Si}$ at 3DIV (Fig. 4A) and a number of them were still seen at 18DIV (Fig. S4E†). It was also possible to discern short processes within the cell clusters, particularly at 18DIV (Fig. S4E†). The level of arrestin expression was reduced in cells cultured on $\mathrm{Si} \mathrm{NW}$ compared to flat $\mathrm{Si}$ and no labeled processes were observed on the Si NW surfaces (Fig. 4B and S4F $\dagger$ ). Rods were also observed on both substrates at 3DIV and 18DIV. On flat $\mathrm{Si}$, rhodopsin-positive cells situated in clusters were seen to extend short processes at 3DIV (Fig. 4C), which were not observed at 18DIV (Fig. 4E). Labeled rods on Si NW, on the other hand, did not exhibit processes at any of the time points (Fig. 4D and F). Yet, the same exposure time could be used to image rhodopsin positive cells on both flat $\mathrm{Si}$ and $\mathrm{Si}$ NW, which, as described above, was not the case for any of the other markers.

\section{Effect of Si NW topography}

The most prominent cell phenotype observed was the absence of cellular processes on Si NW substrates. This result was unexpected since nanowire-structured surfaces have
Si flat
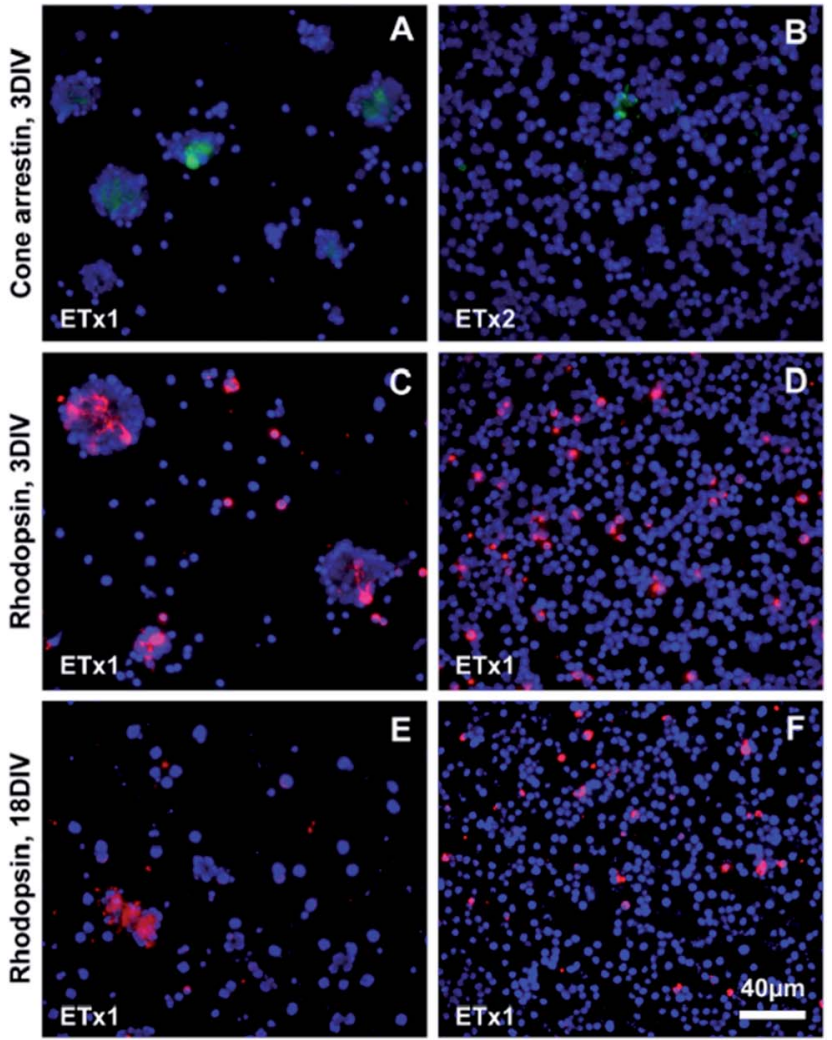

Fig. 4 Fluorescence images of retinal cell cultures after 3DIV showing cone arrestin-positive cells (green) and cell nuclei (DAPI, blue) on flat $\mathrm{Si}$ (A) and Si NW (B) substrates, and rhodopsin positive cells (red) and cell nuclei (DAPI, blue) on flat Si (C) and Si NW (D) substrates. Fluorescence images of retinal cell cultures after 18DIV showing rhodopsin positive cells (red) and cell nuclei (DAPI, blue) on flat Si (E) and Si NW (F) substrates. The Exposure Time (ET) required to image the cone arrestin-positive cells was longer on Si NW substrates; increased by a factor that is indicated at the bottom left of the panel. Scale bar, $40 \mu \mathrm{m}$ for all panels.

been previously shown to promote neurite elongation..$^{20,22,27}$ Since processes were observed on Si flat substrates, we investigated whether NW with intermediate lengths would be better in supporting outgrowth. By varying the etching time, we fabricated $0.8 \mu \mathrm{m}$ and $1.8 \mu \mathrm{m}$ long Si NW and cultured cells for 3DIV. This resulted in the same cell behavior as seen with the standard $4.4 \mu \mathrm{m}$ long NW (not shown). Using an even shorter etching time, which lead to an etching depth of $0.2 \mu \mathrm{m}$ (Fig. S5C $\dagger$ ), not only allowed the extension of neurites, which were observed at both 3DIV and 18DIV (Fig. S5A-B and $\mathrm{D}^{\dagger}$ ), but even seemed to favor this process compared to flat $\mathrm{Si}$ substrates. This confirms that changing the topography could improve the cell behavior. However, the surface with $0.2 \mu \mathrm{m}$ etching depth, despite providing roughness, does not consist of high aspect ratio structures. Since none of the other tested lengths were seen to support any degree of neurite outgrowth, it seemed that the Si NW topography was not the only factor affecting the cell behavior. 


\section{Effect of contaminants}

A common feature of Si NW substrates is that the exposed surface area is high. Effects associated with the surface, such as silicon degradation, which would be negligible in a $\mathrm{Si}$ flat surface, could therefore significantly affect the properties of the substrate and ultimately cell behavior. A certain degree of degradation would be expected as Si NW (and pSi materials in general) have been shown to degrade in $\mathrm{PBS}^{7,28}$ and culture medium. ${ }^{16}$ In the present study, SEM analysis of $4.4 \mu \mathrm{m}$ long $\mathrm{Si}$ NW substrates following cell culture for 3DIV or 18DIV did not reveal obvious changes in topography (Fig. $1 \mathrm{~A}$ and $2 \mathrm{~F}$, inset).

Another effect associated with the high porosity of Si NW surfaces is the release of fabrication contaminants. In order to assess this possibility, retinal cells were cultured for 3DIV on patterns alternating $\mathrm{Si} \mathrm{NW}$ and flat $\mathrm{Si}$ in the same substrate (Fig. 5A). Cells did not form clusters nor extended processes in the areas occupied by Si NW, but interestingly, also not in the

\section{Si flat + Si NW}
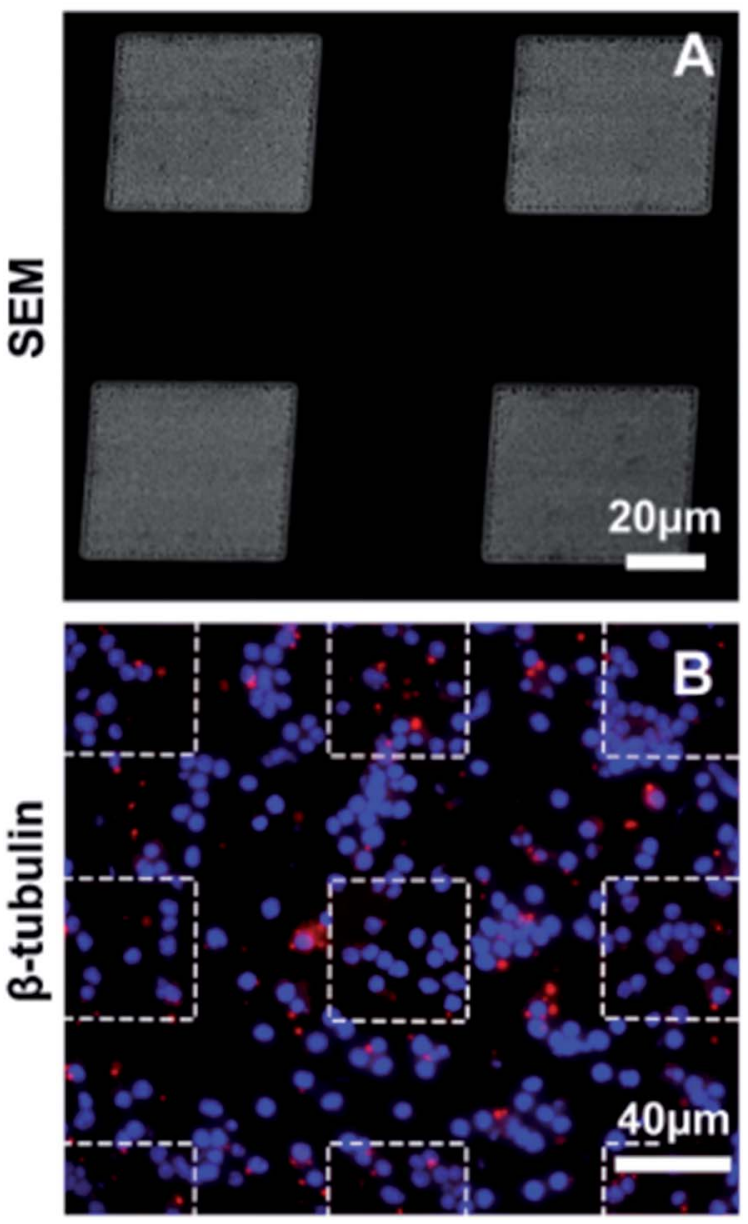

Fig. 5 SEM image of the Si substrate with $50 \times 50 \mu \mathrm{m}^{2}$ areas of nanowires, spaced by $50 \mu \mathrm{m}$ (A). Fluorescence image of retinal cell cultures after 3DIV showing cell nuclei (DAPI, blue) and $\beta$-tubulin III positive cells (red) on the Si NW-flat Si patterned substrate (B). Scale bar, $20 \mu \mathrm{m}$ for SEM image (tilt $30^{\circ}$ ). Scale bar, $40 \mu \mathrm{m}$ for the fluorescence image. substrate flat areas (Fig. 5B). These observations corroborate the assumption that contaminants may be released from the NW and are responsible for the altered cell behavior now observed even in the neighboring areas with flat silicon.

We then considered three possible contaminants that could derive from the process of Si NW fabrication: silver (Ag), nitric acid $\left(\mathrm{HNO}_{3}\right)$, and hydrofluoric acid (HF). The reduction of silver ions in the $\mathrm{HF} / \mathrm{AgNO}_{3}$ solution generates silver particles, which catalyze the etching of silicon. Such particles are normally removed by soaking the substrate in $\mathrm{HNO}_{3}$ (see Material and Methods for details). To test whether residual silver particles could contribute to alter the cell behavior, we cultured retinal cells for 3DIV on flat Si substrates decorated with a high density of silver nanoparticles (Fig. 6A, inset). It was found that the cells were still able to form clusters and to extend processes, similar to cells on control flat Si substrates (Fig. 6A).

We also cultured retinal cells for 3DIV on flat $\mathrm{Si}$ in the presence of $\mathrm{HNO}_{3}$ and found that the cell behavior was not altered by the concentrations tested $\left(10^{-3} \mathrm{M}\right.$ and $\left.10^{-4} \mathrm{M}\right)$ (Fig. 6B). Finally, cells were cultured on flat Si substrates in the presence of another potential contaminant, HF, which was added to the cell medium at final concentrations of $10^{-3}$ $\mathrm{M}$ and $10^{-4} \mathrm{M}$. While the lower concentration had no effect on cell behavior (not shown), no cell clusters could be found at the higher concentration. Instead, a dense layer of single
Si flat + Ag NP ( $\beta$-tubulin)

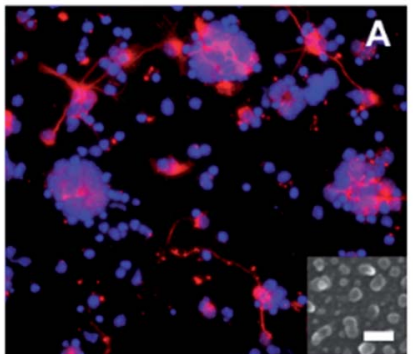

Si flat + HF ( $\beta$-tubulin)

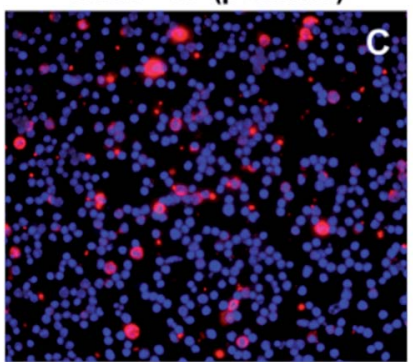

Si flat $+\mathrm{HNO}_{3}$ ( $\beta$-tubulin)

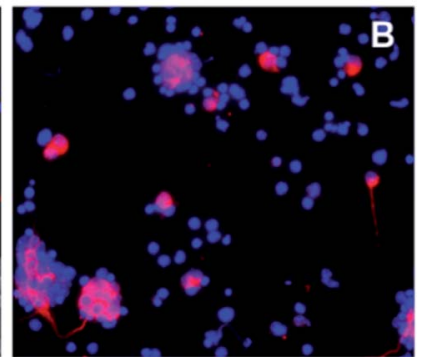

Si flat + HF (Rhodopsin)

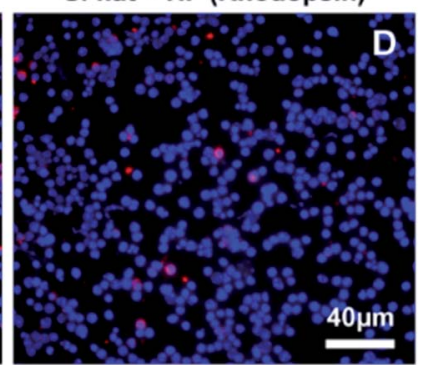

Fig. 6 Fluorescence images of retinal cell cultures after 3DIV showing in (A) cell nuclei (DAPI, blue) and $\beta$-tubulin III positive cells (red) on the Si substrates with $\mathrm{Ag}$ nanoparticles (the inset shows the Ag nanoparticles). In (B), fluorescence images of the retinal cell cultured for 3DIV with $\mathrm{HNO}_{3}$ at a concentration of $10^{-3} \mathrm{M}$ on Si flat substrates, showing cell nuclei (DAPI, blue) and $\beta$-tubulin III positive cells (red). Fluorescence images of the retinal cell cultured for 3DIV with $\mathrm{HF}$ at a concentration of $10^{-3} \mathrm{M}$ on Si flat substrates showing cell nuclei (DAPI, blue) and $\beta$-tubulin III positive cells (red) (C), and cell nuclei (DAPI, blue) and rhodopsin positive cells (red) (D). Scale bar, $40 \mu \mathrm{m}$ for fluorescence images. Scale bar, $50 \mathrm{~nm}$ for the inset in (A) (top view). 
cells was observed in the samples both at 3DIV (Fig. 6C) and 18DIV (not shown), resembling the cell behavior observed with Si NW substrates. Immunoreactivity corresponding to $\beta$-tubulin III showed that, similarly to what was seen with $\mathrm{Si}$ NW, the level of protein expression seemed to be lower compared to flat controls without $\mathrm{HF}$ and cells lacked processes (Fig. 6C). A number of cells also expressed rhodopsin (Fig. 6D), and the level of expression appeared to be similar to that observed on both flat $\mathrm{Si}$ (without HF) and $\mathrm{Si}$ NW substrates. These observations suggest that HF, released from the Si NW substrate, is at least one of the factors affecting the cell behavior.

\section{Effects of substrate cleaning}

With the purpose of removing possible contaminants (such as $\mathrm{HF}$ ), we examined whether further cleaning of the Si NW surface could affect the cell behavior. The NW substrates were put through the following extra cleaning steps: overnight water bath incubation, exposition to high vacuum, and oxygen plasma. SEM inspection did not show any obvious modification of the substrate topography after cleaning (Fig. S6 $\dagger$ ). Cells cultured for 3DIV in these substrates exhibited the same cell behavior normally observed in standard Si NW, suggesting that the tested cleaning steps were insufficient (Fig. S6†).

\section{Effects of surface coating}

Modifications of the Si NW surface chemistry could be used to limit the exposure of the cells to contaminants. Substrates were coated with BSA (Fig. S10A $\dagger$ ), which is widely used for surface passivation. $^{29}$ At $3 \mathrm{DIV}$, cells still exhibited the same cell behavior observed with bare Si NW, without cluster formation nor neurite extension (Fig. S7A $\dagger$ ). We also tested the effect of PDL-Laminin (Fig. S10B $\dagger$ ), which in addition to coating the surface, would be expected to stimulate neurite outgrowth. ${ }^{30}$ This modification had also no effect on the cell behavior (Fig. S7B $\dagger$ ).

In oxidized silicon surfaces, silane molecules react with silanol groups and form a dense assembly of molecules covalently bonded to the surface. Such molecules could therefore be expected to provide an efficient barrier against the contaminants. We functionalized Si NW substrates and flat $\mathrm{Si}$ control substrates with perfluorosilane (PFS; Fig. S10D $\dagger$ ) and found that on all substrates, single cells and cell clusters were observed both at 3DIV and 18DIV, expressing markers as on flat Si substrate (Fig. 7C and D, Fig. S8A-F and S9A-F†). Further, short, labeled neurites were observed within the cell clusters or between them when using $\beta$-tubulin III (Fig. 7C and D, and S9A and $\mathrm{B} \dagger$ ), rhodopsin and TRPV-4 at 3DIV and 18DIV (Fig. S8A-D and S9C-F $\dagger$ ), resembling the cell behavior observed with flat, uncoated $\mathrm{Si}$ substrates. Staining of cells cultured in PFS-coated Si NW for GFAP, revealed also a few glial cells exhibiting a flat, polygonal shape and in association with the clusters at both time points (Fig. S8E and $\mathrm{F}^{\dagger}$ ).
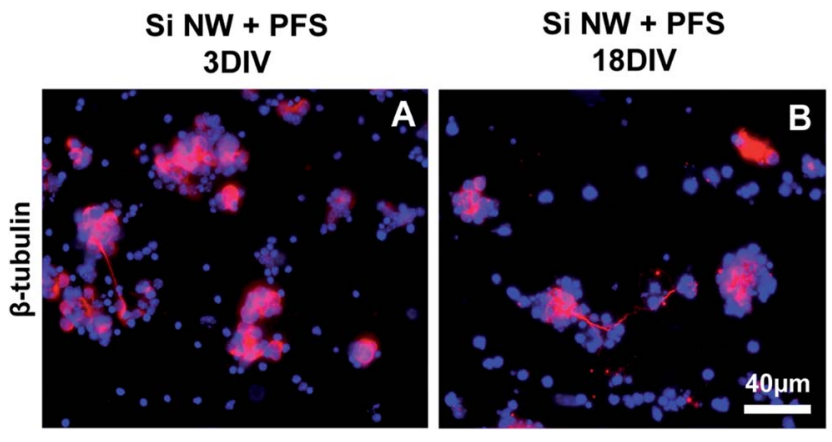

Fig. 7 Fluorescence images of retinal cell cultures showing cell nuclei (DAPI, blue) and $\beta$-tubulin III positive cells (red) after 3DIV (A) and 18DIV (B) on Si NW substrates previously functionalized with perfluorosilanes (PFS). Scale bar, $40 \mu \mathrm{m}$ for both panels.

\section{Discussion}

We have examined short term- and long-term cultures of retinal cells on Si and Si NW substrates and shown that cells survive and express retinal markers on both types of substrates for at least 18DIV. The cultures on Si NW were, however, characterized by a dense layer of strongly adhering single cells and the absence of cell clusters, which were otherwise observed in cultures on flat Si. Markers identifying cone photoreceptors, bipolar cells, ganglion cells and glial cells were found in both substrates, but were all under-expressed in Si NW compared to flat Si. Interestingly, however, the level of rhodopsin expression in rod photoreceptors was similar in both substrates. Moreover, all cells labeled with these markers could be seen to extend processes on flat Si but never on Si NW.

Previous cell studies on porous $\mathrm{Si}$ have shown that the topography, specifically pore size and depth, influence greatly the cell phenotype. ${ }^{11,13,31,32}$ In the present study, we found that both, flat Si and Si substrates with a small etching depth (0.2 $\mu \mathrm{m})$, allowed the occurrence of cell clusters and of cell processes. In contrast, this cell behavior was never observed in 0.8-4.4 $\mu \mathrm{m}$ long Si NW, not even after only 1DIV. This is in contrast to what we have found when culturing retinal cells on gallium phosphide nanowires (GaP NW), using the same protocol as here. ${ }^{22}$ With GaP NW, longer nanowires $(4 \mu \mathrm{m})$ promoted better attachment and a much more extensive neurite outgrowth than shorter nanowires ( 0.5 or $1 \mu \mathrm{m}$ long). On the other hand, the cell behavior we observed using a small etching depth $(0.2 \mu \mathrm{m})$ appears to confirm previous observations made using e.g., primary cortical neurons. ${ }^{33}$ In that study, it was found that a silicon surface with a roughness of $64 \mathrm{~nm}$ produced an even better outcome than surfaces with a roughness of around $0.2 \mu \mathrm{m}$. The roughness of these samples was determined using atomic force microscopy (AFM), while nanowires are not suitable for this type characterization, due to their high aspect ratio, making direct comparisons with our results difficult. Nevertheless, it was suggested in their study that the $64 \mathrm{~nm}$ surfaces would provide a better contact area for the cells, allowing for better attachment and neurite extension. 
A quantification of cells attached to the surfaces could not be performed in the present study, as it was not possible to estimate the number of cells in the clusters on flat Si. However, it was seen that areas devoid of cells were larger and more frequent at 18DIV than at 3DIV in flat Si substrates, suggesting that, with time, cells had detached from the surface. We have previously observed poor cell adhesion and/or increased cell detachment on planar glass and gallium phosphide substrates. ${ }^{20,22}$ It is possible that roughness favors the deposition of proteins that support stable cell attachment, a process that may be limited in flat surfaces..$^{20,22}$ Areas devoid of cells were not observed with Si NW at any time point, suggesting that cell attachment was in fact better on Si NW than on flat Si. The surface features of the long Si NW used here seemed thus to allow good attachment, despite a clear negative effect on the process of neurite elongation. It should be noted that cell adhesion and neurite extension are two distinct processes, where under the same conditions, one might observe good cell adhesion but not neurite outgrowth. ${ }^{34}$

The extension of neurites and the motility of growth cones are regulated by the complex interaction between extracellular cues, such as growth factors, cell adhesion molecules, mechanical forces, and components of the cytoskeleton, as well as activation of specific intracellular signaling cascades (reviewed in ref. 35-37). Cells on Si NW substrates expressed various retinal cell markers even at 18DIV, but the level of expression was in most cases considerably lower than that of cells on flat Si. It is possible that the levels of proteins essential for the process of neurite elongation were also low and insufficient to support outgrowth. Moreover, we found that on Si NW substrates, the expression of the glial intermediate filament, glial fibrillary acidic protein (GFAP), was also reduced, and that glial cells were round and lacked any cytoplasmic extensions. In a recent report, it was shown that the most extensive neurite outgrowth was observed in retinal explants derived from mice over-expressing GFAP. ${ }^{38}$ It was then suggested that the glial cells in these mice provide a better scaffold supporting retinal ganglion cell neurite elongation than the glial cells in mice expressing normal or low GFAP levels. We have also shown previously, in an in vivo model of retinal transplantation, that sprouting neurites were only seen in association with GFAP expressing glial processes. ${ }^{39}$ It is thus possible that the inability of glial cells to extend processes and express GFAP on Si NW also contributed to limit the elongation of neuronal processes on this substrate. Another glial cell study reports, however, that primary cortical astrocytes preferably adhere and extend processes on dry etched Si grass (another pillar-like topography in $\mathrm{Si}$ ), compared to a smoother topography. It should be noted though that Si grass is characterized by pillars of lower aspect ratio compared to the material used in the present study. ${ }^{18}$

In any case, differences in topography cannot alone explain the different cell behavior as we found that the phenotype of cells cultured on mixed patterns of $\mathrm{Si} \mathrm{NW}$ and flat $\mathrm{Si}$ was the same as that seen on Si NW substrates. This suggested that factors associated with the presence of NW modified the culture conditions. Contaminants may arise from either chemical reactions between silicon and the biological medium and/or from residues of chemicals derived from the NW etching, which become trapped in the pores. A degradation of the NW would potentially allow an enhanced release of such contaminants from the porous substrate to the cell surroundings, contributing to the observed cell phenotype on Si NW. Although we did not observe any significant topography changes on Si NW substrates after cell culture, we cannot rule out the possibility that some degradation took place, since it has been shown that oxidized silicon is not stable in aqueous media. ${ }^{6,716,40}$

High aspect ratio nanowire substrates yield a large loading reservoir for contaminants thanks to their higher porosity and the fact that the nanowires coalesce after etching (see Fig. 1). It may thus be assumed that even with minimal Si NW degradation, cells attached to such substrates will be exposed to the contaminants. The fact that in mixed pattern substrates, cells attached to the flat surface areas were also affected suggests that the contaminants are gradually released, as they diffuse into the medium. The observation that cells exhibited neurite extension and formed clusters on the $0.2 \mu \mathrm{m}$ etching depth substrates also supports the hypothesis that the altered cell behavior on Si NW may be attributed, at least in part, to exposure to the contaminants. Indeed, with the shallow etching depth, the material has very little porosity and the surface area is not appreciably increased compared to the flat substrate, retaining insignificant amounts of contaminants, or amounts that are easily washed away. Similarly, exposing cells to free-floating Si NW may not result in phenotypic alterations, since contaminants trapped underneath coalesced nanowires would be released upon detaching the nanowires from the substrate, before they were put in contact with the cells.

Adding HF to cell cultures on flat Si resulted in the same cell phenotype as the one observed on Si NW substrates (good adhesion, lack of cell clusters and of neurites), suggesting that residues from HF trapped in the porous material after etching may be responsible for the changes in cell behavior observed on Si NW. HF reacts with water to form fluoride ions, which in turn reacts with calcium to form calcium fluoride, an insoluble salt. ${ }^{41}$ The presence of $\mathrm{HF}$ in the cell medium could, for instance, diminish the amount of available calcium, which is an important ion involved in numerous cell functions, including cell adhesion and neurite outgrowth (reviewed in ref. 42) It is thus possible that residual HF contributed to a suppression of neurite outgrowth. This hypothesis is supported by observations made in previous studies using Si NW synthesized by chemical vapor deposition or dry etching methods (which do not involve HF) and where neural precursor cells and embryonic brain cells could be seen extending neurites. ${ }^{43,44}$ Our observations conform also with those made previously, where non-neural cells cultured on the same substrates as in the present study, showed increased cell adhesion but decreased cell spreading on NW compared to flat controls, similar to what we observed in our cultures, however, without linking the phenotype to HF. ${ }^{45}$ Interestingly, though, another study showed that PC12 cells extend more neurites on Si NW etched using HF, compared to flat controls, which contrasts with our results. ${ }^{11}$ This discrepancy may be attributed to the fact that primary neurons from the central nervous system (CNS), like the retinal cells used 
here, are possibly more sensitive to contaminants compared to more robust, immortalized cells such as PC12 cells.

Our data thus suggests that the modified cell phenotype observed with Si NW, which were prepared using MACE, may be attributed to residual HF in the material. Further, in addition to exogenous contaminants derived from the fabrication method, compounds arising from the material itself may also affect cell behavior, such as silicic acid $\left(\mathrm{Si}(\mathrm{OH})_{4}\right)$, which is produced upon oxidized silicon reaction with water. ${ }^{8}$ Our attempts to clean the Si NW substrates did not change the cell phenotype, indicating that it is difficult to mobilize molecules entrapped in such high aspect ratio substrates.

Our study also shows that it is possible to prevent the altered cell phenotype by using a surface coating. Modifying the Si NW surface with covalently bonded perfluorosilane molecules resulted in what appears to be a stable coating of the nanowires, which probably limited the exposure to contaminants, allowing the formation of cell clusters and neurite outgrowth. In addition to reacting with the oxidized silicon material surface, it is possible that silanes have reacted with residual water and released silicic acid to form a gel. This would result in an obstruction of the pores, decreasing the release of contaminants sufficiently to allow for proper cell growth. Moreover, as discussed above, since our method for assessing material degradation was based on visual assessment of SEM images, we cannot exclude that a certain degree of degradation of the Si NW did occur. In this case, it is thus possible that changes in the kinetics of material degradation have also played a role in the phenotype observed when using silane molecules. Aminosilanes and octadecyltrichlorosilanes have previously been shown to protect Si NW from degradation. ${ }^{16,46}$ We can speculate that this applies also to other silane molecules, since they form a dense and homogeneous layer on oxidized silicon, ${ }^{47,48}$ which would slow down considerably the degradation of the material and the release of the contaminants. The use of such coating, however, would limit or prevent not only the release of contaminants, but also that of loaded therapeutic compounds, making the material virtually incompatible with drug release.

It should be noted also that different cell types may be differentially sensitive to contaminants entrapped in the Si NW substrates and that CNS neurons are particularly susceptible. In this context, however, it is interesting that in our cultures, rod photoreceptors on Si NW were still able to express rhodopsin at levels comparable to rods on flat Si even at 18DIV. These cells are otherwise particularly vulnerable and die in pathological conditions affecting the retina ${ }^{49}$ (http://www.sph.uth.tmc.edu/Retnet/ RetNet is provided in the public domain by the University of Texas Houston Health Science Center, Houston, TX). At the age at which cells were harvested for culture (PN4), the cell suspension contained immature post-mitotic rod precursors, which others and we have shown are more apt to integrate with the host retina following subretinal transplantation. ${ }^{\mathbf{5 0 , 5 1}}$ It is possible that at this stage, rod photoreceptors are somehow also more resistant to the toxic effects of the contaminants. Whether or not cultures of retinal cells on Si NW could provide a useful approach to generate an enriched population of photoreceptor precursors for rod cell replacement or other purposes would need to be analyzed.

\section{Conclusion}

High aspect ratio porous Si NW substrates have been proposed as a means to deliver drugs at a slow rate. The data obtained in the present study show that such NW substrates, while easy to make and relatively inexpensive, do not allow the formation of neuronal networks in cultures of retinal cells. We attribute this phenotype to the presence of contaminants entrapped in the material, which could not be removed despite thorough cleaning. It appears thus, that the very same property that grants these substrates suitable for slow drug delivery (high porosity) can pose a problem. It can be concluded from these data that problems associated with the porosity of Si NW, at least those prepared using MACE, must be carefully characterized, especially if designed to interface with cells from the CNS.

\section{Acknowledgements}

The authors would like to thank Drs Robert S. Molday and Cheryl Craft for the generous gift of antibodies, Hodan Abdshill for assistance with retinal dissection and preparation of media, Birgitta Sandström for maintaining the animal colony and Shantonu Biswas for help with fabrication of the nanowires. Gaëlle Piret was financed by a postdoctoral grant from the Lund Tekniska Högskola (LTH) at Lund University. The study was supported by the Nanometer Structure Consortium (nmC@LU), the Swedish Research Council, VELUX STIFTUNG, Crown Princess Margareta's Committee for the Blind, Stf för Synskadade fd Malmöhus Län, Edwin Jordans Stiftelse för Oftalmologisk Forskning, Gun och Bertil Stohnes Stiftelse, Greta och Johan Kocks Stiftelse, Magnus Bergvalls Stiftelse, and the Neuronano Research Center at Lund University.

\section{References}

1 F. Lapierre, G. Piret, H. Drobecq, O. Melnyk, Y. Coffinier, V. Thomy and R. Boukherroub, Lab Chip, 2011, 11, 16201628.

2 R. J. Martin-Palma, M. Manso-Silvan and V. Torres-Costa, J. Nanophotonics, 2010, 4(1), 042502.

3 G. Piret, R. Desmet, E. Diesis, H. Drobecq, J. Segers, C. Rouanet, A.-S. Debrie, R. Boukherroub, C. Locht and O. Melnyk, J. Proteome Res., 2010, 9, 6467-6478.

4 G. Piret, H. Drobecq, Y. Coffmier, O. Melnyk and R. Boukherroub, Langmuir, 2010, 26, 1354-1361.

5 G.-J. Zhang and Y. Ning, Anal. Chim. Acta, 2012, 749, 1-15.

6 E. J. Anglin, L. Y. Cheng, W. R. Freeman and M. J. Sailor, $A d v$. Drug Delivery Rev., 2008, 60, 1266-1277.

7 K. S. Brammer, C. Choi, S. Oh, C. J. Cobb, L. S. Connelly, M. Loya, S. D. Kong and S. Jin, Nano Lett., 2009, 9, 3570-3574.

8 J. Salonen, A. M. Kaukonen, J. Hirvonen and V. P. Lehto, J. Pharm. Sci., 2008, 97, 632-653.

9 F. Peng, Y. Y. Su, X. P. Wei, Y. M. Lu, Y. F. Zhou, Y. L. Zhong, S. T. Lee and Y. He, Angew. Chem., Int. Ed., 2013, 52, 14571461.

10 Y. W. Fan, F. Z. Cui, L. N. Chen, Y. Zhai, Q. Y. Xu and I. S. Lee, Appl. Surf. Sci., 2002, 187, 313-318. 
11 K. A. Moxon, S. Hallman, A. Aslani, N. M. Kalkhoran and P. I. Lelkes, J. Biomater. Sci., Polym. Ed., 2007, 18, 1263-1281.

12 K. A. Moxon, N. M. Kalkhoran, M. Markert, M. A. Sambito, J. L. McKenzie and J. T. Webster, IEEE Trans. Biomed. Eng., 2004, 51, 881-889.

13 F. Johansson, M. Kanje, C. E. Linsmeier and L. Wallman, IEEE Trans. Biomed. Eng., 2008, 55, 1447-1449.

14 F. Johansson, L. Wallman, N. Danielsen, J. Schouenborg and M. Kanje, Acta Biomater., 2009, 5, 2230-2237.

15 J. M. Lopacinska, C. Gradinaru, R. Wierzbicki, C. Kobler, M. S. Schmidt, M. T. Madsen, M. Skolimowski, M. Dufva, H. Flyvbjerg and K. Molhave, Nanoscale, 2012, 4, 3739-3745.

16 G. Piret, E. Galopin, Y. Coffinier, R. Boukherroub, D. Legrand and C. Slomianny, Soft Matter, 2011, 7, 86428649.

17 A. Ranella, M. Barberoglou, S. Bakogianni, C. Fotakis and E. Stratakis, Acta Biomater., 2010, 6, 2711-2720.

18 S. Turner, L. Kam, M. Isaacson, H. G. Craighead, W. Shain and J. Turner, J. Vac. Sci. Technol., B, 1997, 15, 2848-2854.

19 W. Hallstrom, M. Lexholm, D. B. Suyatin, G. Hammarin, D. Hessman, L. Samuelson, L. Montelius, M. Kanje and C. N. Prinz, Nano Lett., 2010, 10, 782-787.

20 W. Hallstrom, T. Martensson, C. Prinz, P. Gustavsson, L. Montelius, L. Samuelson and M. Kanje, Nano Lett., 2007, 7, 2960-2965.

21 W. Hallstrom, C. N. Prinz, D. Suyatin, L. Samuelson, L. Montelius and M. Kanje, Langmuir, 2009, 25, 4343-4346.

22 G. Piret, M. T. Perez and C. N. Prinz, Biomaterials, 2013, 34, 875-887.

23 C. Prinz, W. Hallstrom, T. Martensson, L. Samuelson, L. Montelius and M. Kanje, Nanotechnology, 2008, 19, 345101.

24 D. B. Suyatin, W. Hallstram, L. Samuelson, L. Montelius, C. N. Prinz and M. Kanje, J. Vac. Sci. Technol., B, 2009, 27, 3092-3094.

25 K. Q. Peng, Y. J. Yan, S. P. Gao and J. Zhu, Adv. Mater., 2002, 14, 1164-1167.

26 R. Douani, G. Piret, T. Hadjersi, J.-N. Chazalviel and I. Solomon, Thin Solid Films, 2011, 519, 5383-5387.

27 W. Kim, J. K. Ng, M. E. Kunitake, B. R. Conklin and P. D. Yang, J. Am. Chem. Soc., 2007, 129, 7228-7229.

28 C. Chiappini, X. W. Liu, J. R. Fakhoury and M. Ferrari, Adv. Funct. Mater., 2010, 20, 2231-2239.

29 B. Sweryda-Krawiec, H. Devaraj, G. Jacob and J. J. Hickman, Langmuir, 2004, 20, 2054-2056.

30 M. Manthorpe, E. Engvall, E. Ruoslahti, F. M. Longo, G. E. Davis and S. Varon, J. Cell Biol., 1983, 97, 1882-1890.

31 M. Kanje and F. Johansson, Prog. Brain Res., 2011, 194, 253262.
32 Y. L. Khung, G. Barritt and N. H. Voelcker, Exp. Cell Res., 2008, 314, 789-800.

33 S. P. Khan, G. G. Auner and G. M. Newaz, Nanomedicine, 2005, 1, 125-129.

34 J. Bischof, A. Muller, M. Fander, U. Knippschild and D. Fischer, PLoS One, 2011, 6, e20857.

35 V. Lemmon, S. M. Burden, H. R. Payne, G. J. Elmslie and M. L. Hlavin, J. Neurosci., 1992, 12, 818-826.

36 S. D. Skaper, S. E. Moore and F. S. Walsh, Prog. Neurobiol., 2001, 65, 593-608.

37 D. Kiryushko, V. Berezin and E. Bock, Ann. N. Y. Acad. Sci., 2004, 1014, 140-154.

38 K. A. Toops, T. L. Hagemann, A. Messing and R. W. Nickells, BMC Res. Notes, 2012, 5, 693.

39 Y. Zhang, A. K. Kardaszewska, T. van Veen, U. Rauch and M. T. Perez, Invest. Ophthalmol. Visual Sci., 2004, 45, 44404449.

40 S. W. Hwang, H. Tao, D. H. Kim, H. Y. Cheng, J. K. Song, E. Rill, M. A. Brenckle, B. Panilaitis, S. M. Won, Y. S. Kim, Y. M. Song, K. J. Yu, A. Ameen, R. Li, Y. W. Su, M. M. Yang, D. L. Kaplan, M. R. Zakin, M. J. Slepian, Y. G. Huang, F. G. Omenetto and J. A. Rogers, Science, 2012, 337, 1640-1644.

41 J. C. Bertolini, J. Emerg. Med., 1992, 10, 163-168.

42 L. Sheng, I. Leshchyns'ka and V. Sytnyk, Cell Commun. Signaling, 2013, 11, 94.

43 A. K. Shalek, J. T. Robinson, E. S. Karp, J. S. Lee, D.-R. Ahn, M.-H. Yoon, A. Sutton, M. Jorgolli, R. S. Gertner, T. S. Gujral, G. MacBeath, E. G. Yang and H. Park, Proc. Natl. Acad. Sci. U. S. A., 2010, 107, 1870-1875.

44 F. Patolsky, B. P. Timko, G. H. Yu, Y. Fang, A. B. Greytak, G. F. Zheng and C. M. Lieber, Science, 2006, 313, 1100-1104.

45 S. J. Qi, C. Q. Yi, S. L. Ji, C. C. Fong and M. S. Yang, ACS Appl. Mater. Interfaces, 2009, 1, 30-34.

46 S. P. Low, K. A. Williams, L. T. Canham and N. H. Voelcker, Biomaterials, 2006, 27, 4538-4546.

47 H. L. Li, A. P. Fu, D. S. Xu, G. L. Guo, L. L. Gui and Y. Q. Tang, Langmuir, 2002, 18, 3198-3202.

48 C. Prinz, P. Muller and M. Maaloum, Macromolecules, 2000, 33, 4896-4902.

49 K. A. Wunderlich, T. Leveillard, M. Penkowa, E. Zrenner and M.-T. Perez, Invest. Ophthalmol. Visual Sci., 2010, 51, 48094820.

50 R. E. MacLaren, R. A. Pearson, A. MacNeil, R. H. Douglas, T. E. Salt, M. Akimoto, A. Swaroop, J. C. Sowden and R. R. Ali, Nature, 2006, 444, 203-207.

51 J. Sancho-Pelluz, K. A. Wunderlich, U. Rauch, F. J. Romero, T. van Veen, G. A. Limb, P. R. Crocker and M. T. Perez, Invest. Ophthalmol. Visual Sci., 2008, 49, 5602-5610. 